\title{
A method for implantation of a chronically indwelling intravenous catheter in the pigeon
}

\author{
MARK R. LEBERER, RICHARD R. McKNIGHT, and PHILIP WIRTH \\ University of Mississippi, University, Mississippi 98677
}

\begin{abstract}
A procedure is described for infusing liquids directly into the bloodstream of freely moving unanesthetized pigeons. The system can be used for infusing drugs periodically or chronically for many months. Its potential for studying the stimulus properties of drugs, state dependent learning, drug self-administration, as well as the uneonditioned responses to noncontingent intravenous drug administration in pigeons is discussed.
\end{abstract}

There presently exists data relating to the interaction of pharmacological agents with schedule-controlled behavior in the pigeon (Dews, 1955; Kelleher \& Morse. 1968). The intramuscular route of drug administration has been used almost exclusively in these studies. However, the use of the pigeon for studies of drug self-administration, the stimulus properties of drugs, state dependent learning, or simply the unconditioned effects of intravenous drug infusion has been somewhat limited. This limitation may be partially a function of the lack of simple techniques for surgically preparing the pigeon with an intravenous catheter. It is the purpose of this article to describe such a surgical procedure.

\section{CATHETER CONSTRUCTION}

Materials used in the construction of the catheter: $200 \mathrm{~mm}$ of polyethylene tubing (PE20; I.D. = $.015 \mathrm{in.}$. O. D. $=.043 \mathrm{in.}$ ), $50 \mathrm{~mm}$ of medical grade silicone-rubber tubing (Silastic; I.D. $=.020$ in., $O$. D. $=.037$ in.), $25 \mathrm{~mm}$ of vinyl tubing (Tygon; I.D. $=.031$, O.D. $=.1625$ ), a $1.0-\mathrm{cc}$ tuberculin syringe fitted with a 20-ga. needle and chloroform. Table 1 contains a list of materials with vendors and their addresses.

The procedure involves placing the Silastic tubing in a container of chloroform and allowing it to stand for a minute or two until the tubing is soft and pliable. The tubing can then be pushed over the PE tubing for a distance of $10-15 \mathrm{~mm}$. When the Silastic dries. it provides a tight leakproof fit with the PE. A 45-deg bevel is cut on the Silastic tip of the catheter to facilitate placement into the vein. The PE end of the catheter is placed into the $30-\mathrm{mm}$ length of vinyl tubing which is placed on the needle of the 1-cc syringe filled with physiological saline.

Reprints may be obtained from Richard McKnight, Psychology Department, University of Mississippi, University. Mississippi 38677. The present surgical description is based in part on a procedure first developed while Philip Wirth was a research assistant supported by U. S. Public Health Service Grant MH-13570-03 awarded to Dr. W. F. Crowder.
Table 1

List of Materials Used in This Preparation With Vendors and Addresses*

DRUGS

Chloroform

Humco Laboratories

Texarkana, TX-AR and

local pharmacies

Chlor-mag-pent

Curts Laboratories, Inc.

Penicillin

Kansas City, MO 64105

Elli Lilly and Co.

Indianapolis, IN 46206

SURGICAL SUPPLIES

Disposable needles and syringes Becton-Dickenson

Polyethylene tubing (PE)

Rutherford, NJ 07070

Clay-Adams

299 Webro Road

Parsyppany, NJ 17054

Silastic tubing

V. Mueller and Co. 6600 West Touhy Avenue Chicago, IL 60648

Surgical gauze sponge

Various manufacturers, local pharmacies Scientific Products

Surgical instruments (e.g., scalpels, forceps, scissors, etc.) McGaw Park, IL 60085

Surgical silk

Ethicon Inc

Somerville, NJ 08876

Vinyl tubing

Cole-Parmer Instruments Co.

7425 N. Oak Park Avenue

Chicago, IL 60680

Wound clips and applicator Clay-Adams (cited above) MISCELLANEOUS

Needle tubing

Small Parts Inc.

6901 N.E. Third Avenue

Miami, FL 33138

Leak-proof swivels

BRS/LVE

5301 Holland Drive

Beltsville, MD 10705

* Some of these supplies may be obtained from local surgical supply outlets or pharmacies. For a more extensive list of vendors that supply certain of the above items see: Sidowski. Joseph B. Buyer's Guide. American Psychologist, 1975, 30(3), 445-468.

\section{SURGICAL PROCEDURE}

The bird is anesthetized ${ }^{1}$ with $2 \mathrm{ml} / \mathrm{kg} / \mathrm{IM}$ chlor-mag-pent. The initial injection of the drug may 


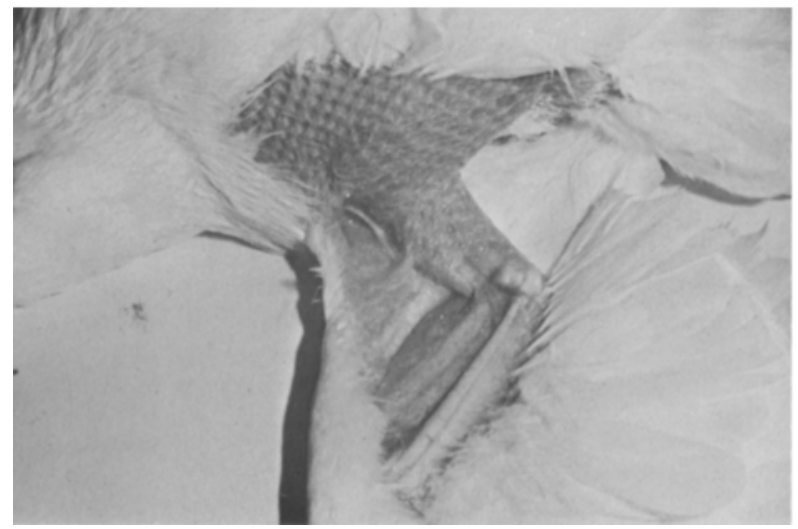

Figure 1. Photograph of an anesthetized pigeon with the feathers removed from the vicinity where the incision is to be made.

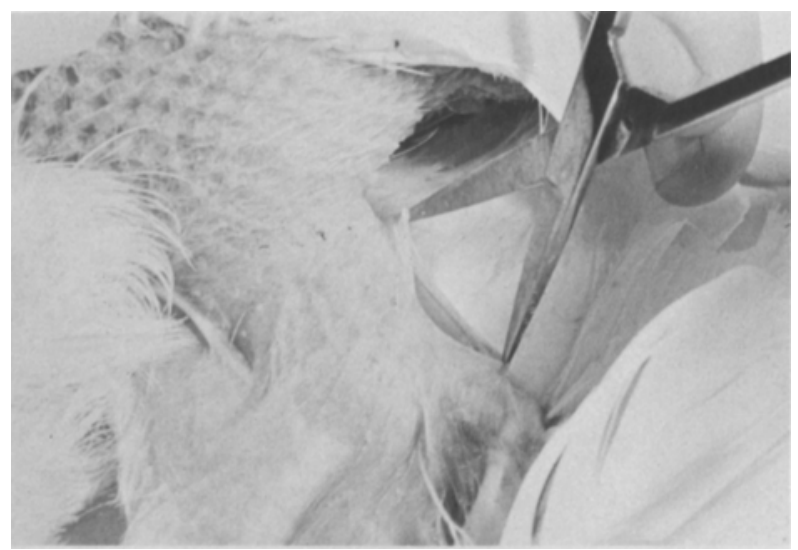

Figure 2. Photograph illustrattng technique for opening the wound on the wing.

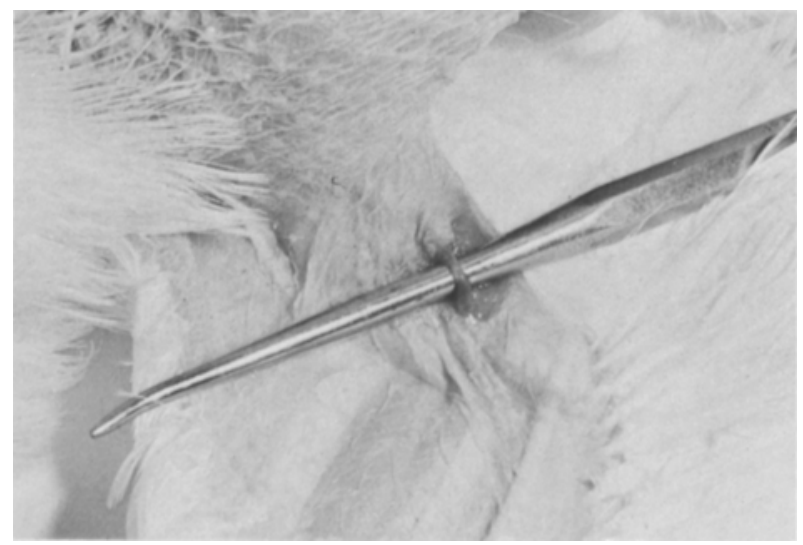

Figure 3. Photograph of the wing vein in isolation with epidermis retracted. The fascin has been removed from the vein to facilitate needle insertion.

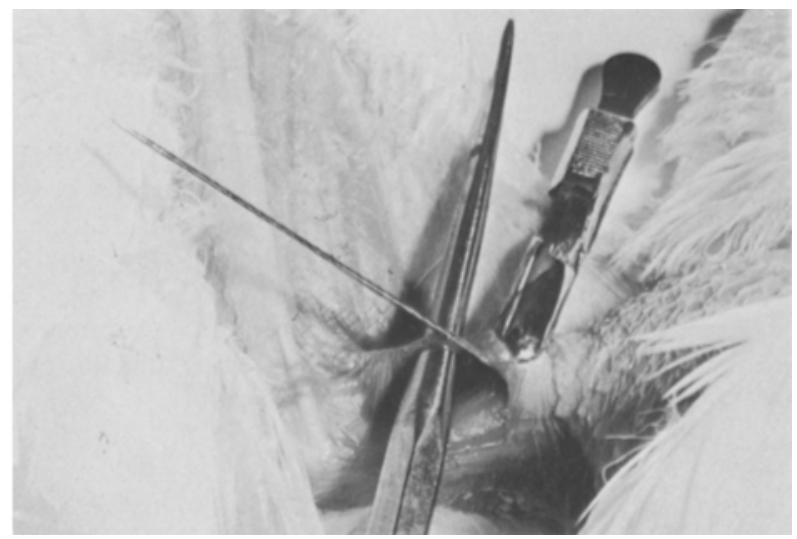

Figure 4. Photograph of the wing vein in isolation with a straight surgical needle inserted.

not produce full anesthesia and subsequent doses of .1 to $.2 \mathrm{ml}$ may be given at intervals of $15-20 \mathrm{~min}$ until the pigeon ceases to respond to the plucking of wing feathers. Other anesthetics may be used also (Webster \& Holland, 1973).

Once the bird is fully anesthetized (typically 20-30 min following initial injection), the feathers are removed from the under side of one wing. All feathers are cleared from the elbow to the breast (See Figure 1). With feathers removed, a pair of veins is visible through the epidermis. Swabbing the area with alcohol facilitates seeing the veins which extend from the elbow to the torso. The more posterior of the two veins (the one nearer the triceps) is catheterized since it lies farther from the brachial artery. This major wing artery lies just below the more anterior of the two veins.

With the wing veins clearly in view, an incision is made through the epidermis just posterior to the vein (i.e., over the triceps approximately $2-3 \mathrm{~mm}$ from the chosen vein). The incision is made by applying light pressure with the closed tips of a pair of surgical scissors and by carefully opening the blades (see Figure 2). The procedure is repeated until the incision is deep enough to insert a blunt probe beneath the vein. The probe is manipulated so that the tip presses upward against the connective tissue between the two veins. Carefully rubbing a scalpel blade against the probe tip opens a hole between the veins. The next step is to insert the scissors in this hole and very carefully open the blades in order to separate the veins for a length of about $2 \mathrm{~cm}$. The probe is then placed under the vein so as to lift it up from the surrounding tissue (see Figure 3).

Once the vein is isolated and cleared, it is pierced with a small-gauge straight stainless steel surgical needle. The tip of the needle is inserted into the lumen of the vein in the direction of the torso. A second needle is then inserted alongside the first (see Figure 4). 


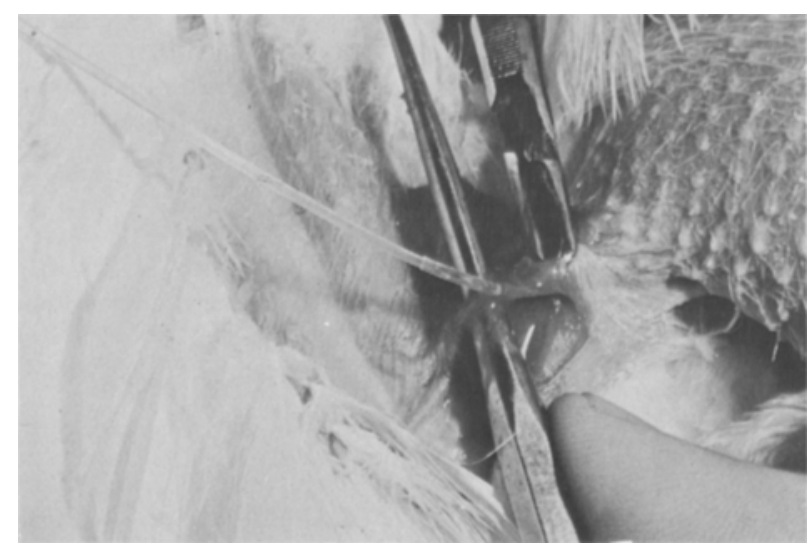

Figure 5. Photograph of the wing vein with the catheter inserted.

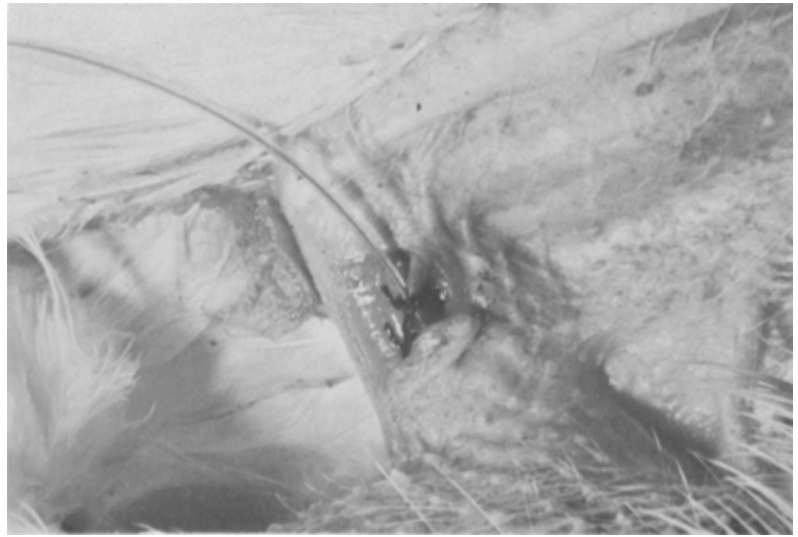

Figure 6. Photograph of the wing vein with the catheter inserted and the sutures tightened. Blood in the catheter mdicates its patency at this point in the procedure.

After these operations are completed, the first needle is removed and the second needle is used as a blunt lever to open a hole in the vein. The second needle (inserted headfirst) is not likely to puncture the vein in the process of enlarging the hole. Using the needle to open the hole and the probe to apply pressure against the vein, the catheter is inserted into the vein with forceps and pushed along the lumen until the junction of the Silastic and PE is just inside the opening in the vein (see Figure 5). Two sutures are taken around the vein; one at the point where the PE and Silastic join (a suture over the Silastic alone cuts off the flow through the catheter), and the other around the vein below the level of the opening. Two more sutures are taken around the catheter and through the adjacent wing muscle. The suture material should not be biodegradable (e.g., surgeon's silk thread; see Figure 6).
At this point. the patency of the catheter is tested by drawing back slowly on the syringe. Blood should appear in the catheter (see Figure 6). The catheter is then washed with $.5 \mathrm{ml}$ of saline from the syringe and the syringe removed. Using an ordinary metal sewing batten, the PE is routed subcutaneously to the back of the neck. A 3-mm-long piece of vinyl tubing is inserted (same type used in conjunction with the syring) over the PE20 and forced below the skin on the neck. The neck and wing are closed with surgical clips; care is necessary not to puncture the PE (see Figure 7). Another $3-\mathrm{mm}$ piece of tubing is lowered over the $\mathrm{PE}$ at the neck and pushed snugly against the wound. The two small pieces of tubing prevent the pigeon from pushing the catheter into the wound or removing it (see Figure 8). Finally, the tip of the catheter is heat sealed until ready for use.

Typically, we allow the bird to recover in a heated cage. Penicillin (100.000 units, IM) is administered daily for 3 days postoperatively. Concurrent with

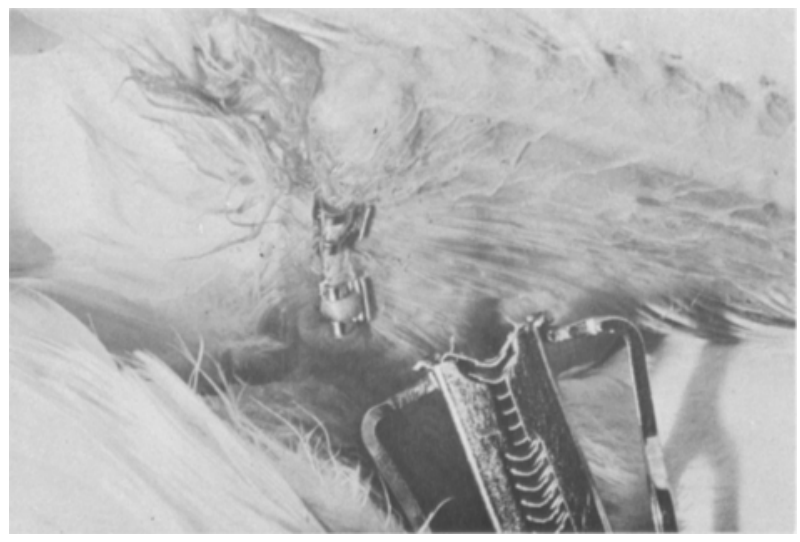

Figure 7. Photograph of the wounds with autoclipe applied. Care should be taken to avoid puncturing the catheter.

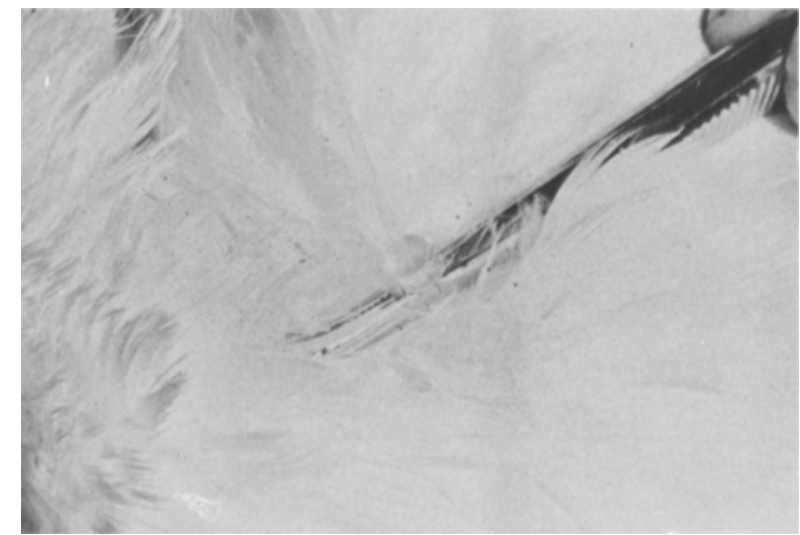

Figure 8. Photograph of the vinyl tubing applied over the catheter as it exits from the back of the neck. 
penicillin injections, we test the patency of the catheter by administering $1 \mathrm{cc}$ of $2 \%$ sodium thiamylal (Surital). The bird should lose muscle control for about 5.10 min following the injection.

\section{PREPARATIONS AND USES}

This preparation is useful in the study of selt-administration of various compounds in the pigeon. Specifically, this involves connecting the cannula to a collar which the pigeon wears around his neck or to a leakproof swivel at the top center of the apparatus.

The operant we chose for drug self-administration work is a turning response. Turning responses are sensed by way of a rotating magnet attached to the needle tubing, which moves through a matrix of reed switches attached to the swivel itself. Using three reed switches, both the direction and the amount of turning (in tridents) necessary to earn a drug infusion can be specitied.

The preparation is also useful in studies that examine the stimulus properties of drugs injected intravenously prior to keypeck responding under concurrent schedules. The procedure has potential for studies examining state dependent learning and conditioned drug effects in pigeons. Since the drugs may be administered automatically while the bird is responding. the preparation may also find utility in the study of the effects of intravenously administered drugs on schedule-controlled behavior in the pigeon.

\section{REFERENCES}

DEws. P. B. The effects of pentobarbital. methamphetamine and scopolomine on performances in pigeons involving discriminations. Journal of Pharmacology and Experimental Therapeutics. 1955, 115, 380-389.

Kelleher, R. T., \& Morse, W. H. Determinants of the speciticity of behavioral effects of drugs. Ergebnisse der Physiologie, 1968, 60, 1-56.

Webster. D. M., \& Holland, V. D. A safe and simple injection anesthetic for birds. Physiology and Behavior, 1973, 10, 831.

\section{NOTE}

1. These drug dosages are based on work with White Carneaux pigeons at least 3 years of age

(Received for publication September 25, 1975; revision received October 27.1975 . 